\title{
Manifestações da cultura popular local na aprendizagem das séries iniciais e na formação dos professores
}

\author{
Nadja Rinelle Oliveira de Almeida \\ Universidade Estadual Vale do Acaraú, Sobral, CE, Brasil \\ Damares de Oliveira Moreiraii \\ Universidade Federal do Ceará, Fortaleza, CE, Brasil
}

\begin{abstract}
Resumo
Este artigo tem o propósito de refletir sobre a relevância das manifestações da cultura popular local para a aprendizagem dos educandos inseridos nas séries iniciais, apontando caminhos para se pensar em como colocamos em cena essas discussões partindo da formação docente e da prática do professor em sala de aula. Fundamentamos teoricamente nossas discussões com os seguintes autores e documentos oficiais: Brandão (2002), Candau e Moreira (2007), (BRASIL, 2006), (BRASIL, 2013), (BRASIL, 2017), Bego (2016), Silva (2008), dentre outros. Para o percurso metodológico optamos pela pesquisa qualitativa de caráter bibliográfico, alinhado as experiências docentes das autoras. Com este percurso foi possível apontar possíveis possibilidades de encontros entre a cultura popular e os saberes constituídos na escola, desde que esses saberes sejam colocados em evidência a partir do ensino de história e de geografia alinhado ao cotidiano dos alunos e dos espaços que ele ocupa em sua cidade.
\end{abstract}

Palavras-chave: Currículo. Cultura local. Séries iniciais.

\section{Manifestations of local popular culture in the learning of the initial grades and in the training of teachers}

\begin{abstract}
This article has the purpose of reflecting on the relevance of the manifestations of the local popular culture for the learning of the students inserted in the initial grades, pointing ways to think about how we put these discussions on the scene starting from the teacher training and the teacher practice in the classroom. We theoretically base our discussions with the following authors and official documents: Brandão (2002), Candau and Moreira (2007), (BRASIL, 2006), (BRASIL, 2013), (BRASIL, 2017), Bego (2016), Silva (2008), among others. For the methodological path, we opted for qualitative research with a bibliographic character, aligned with the teaching experiences of the authors. With this path it was possible to point out possible possibilities of encounters between popular culture and the knowledge constituted in the school, provided that this knowledge is highlighted through the teaching of history and geography aligned with the students' daily lives and the spaces that it occupies in your city.

Keywords: Curriculum. Local culture. Initial series.
\end{abstract}

Rev. Pemo, Fortaleza, v. 2, n. 3, e233726, 2020

DOI: https://doi.org/10.47149/pemo.v2i3.3726

https://revistas.uece.br/index.php/revpemo

ISSN: 2675-519X

(c) (i) Esta obra está licenciada com uma Licença Creative Commons

Atribuição 4.0 Internacional. 


\section{PRÁTICAS EDUCATIVAS, MEMÓRIAS E ORALIDADES}

Rev. Pemo - Revista do PEMO

\section{Introdução}

Analisar como as tradições populares são abordadas no contexto curricular do sistema educacional brasileiro é importante uma vez que há inúmeros questionamentos de como a história local vem sendo explanada e aprofundada nas séries iniciais, tendo em vista a recorrência de discursos que apontam a deficiência dessas discussões no cenário da sala de aula, a partir de uma contextualização mais associada ao cotidiano dos educandos, tendo em vista que cada comunidade tem a sua história e esta precisa ser contada para que haja um processo de pertencimento do local onde este encontra-se inserido.

Nesse contexto entendemos a relevância de refletirmos sobre a concepção de professores e/ou futuros docentes quanto a abordagem das tradições populares na aprendizagem dos alunos. A partir da experiência como docentes de uma disciplina que aborda o ensino de história e geografia nas séries iniciais no Curso de Pedagogia da Universidade Estadual Vale do Acaraú (UVA), percebemos que alguns acadêmicos, como já se encontram atuando em sala de aula, ressaltavam a relevância em se trabalhar a temática com os alunos, e que esta contribui para que possam reconhecer as demais culturas espalhadas pelo mundo.

No entanto, também compreendemos que o uso das manifestações da cultura popular na atuação desses docentes em sala de aula torna-se um desafio, pois embora eles reconheçam a importância de se trabalhar esta temática dando significado, inclusive a atuação desses alunos fora dos muros da escola, isto tem se tornado um desafio proposto pelo próprio sistema de ensino público que busca contemplar, a partir das avaliações em larga escala, a língua portuguesa e a matemática como conteúdos principais para promover de forma exitosa a aprendizagem de discentes.

Com isso é possível perceber que embora os acadêmicos de pedagogia concebam essa necessidade de se trabalhar questões que envolvam a identidade cultural partindo do mundo da vida desses educandos, os mesmos acabam sendo conduzidos por uma visão pragmática onde o ensinar e o aprender devem estar em ressonância com uma

Rev. Pemo, Fortaleza, v. 2, n. 3, e233726, 2020

DOI: https://doi.org/10.47149/pemo.v2i3.3726

https://revistas.uece.br/index.php/revpemo

ISSN: 2675-519X

(c) (i) Esta obra está licenciada com uma Licença Creative Commons

Atribuição 4.0 Internacional. 
doutrinação assegurada pela política de resultados gerida pelos organismos internacionais.

Concordamos com Bego (2016) que o mundo da vida é um aglutinado de elementos que permeiam o mundo da reprodução simbólica e da interação, contendo as situações, relações e realizações cotidianas que são fontes ulteriores de significação. Para o autor, essa esfera é formada pelos subsistemas cultura, sociedade e personalidade; representados pela linguagem e tradição cultural. Com isso, o mundo da vida é, por excelência, a esfera na qual os processos de entendimento ocorrem, uma vez que os "estoques de saberes" legados pela tradição só podem se reproduzir mediante processos expressivos de intersubjetividade partilhados.

$E$ isso pode ser percebido a partir das quadrilhas juninas, por exemplo. Elas fazem parte das manifestações de cultura popular e encontra-se no calendário cultural da cidade e passa a fazer parte dessa tradição cultural que parte dos processos intersubjetivos dos sujeitos. Mas, ao se discutir pedagogicamente ficamos a imaginar de que maneira essa tradição popular é abordada, já que, o tempo para explanação dos conteúdos de história é bem curto e ela geralmente faz parte do calendário das festas realizadas pontualmente no âmbito escolar. Nesta perspectiva cabe questionar: Os alunos dançam quadrilha, mas conhecem a história desta dança?

Conforme o artigo 26 da Lei de Diretrizes e Bases da Educação (LDB) - Lei 9.394/96, os currículos da educação infantil, do ensino fundamental e do ensino médio devem ter base nacional comum, a ser complementada, em cada sistema de ensino e em cada estabelecimento escolar, por uma parte diversificada, exigida pelas características regionais e locais da sociedade, da cultura, da economia e da clientela.

As tradições populares podem ser encontradas na parte diversificada do currículo quando engloba as características regionais e locais, ou seja, a LDB destaca a relevância destes conteúdos fazerem parte do componente curricular. Entretanto, cada sistema educacional de ensino tem autonomia para construir sua proposta pedagógica. Com isso eles podem trazer ou não para o contexto educacional este cenário cultural. 


\section{PRÁTICAS EDUCATIVAS, MEMÓRIAS E ORALIDADES}

Rev. Pemo - Revista do PEMO

Nessa perspectiva, este artigo trilha na intenção de refletir, a partir de algumas discussões teóricas e experienciais, de que maneira podemos problematizar a relevância das manifestações da cultura local para a aprendizagem do educando que se encontra nas séries iniciais, ou seja, apontar caminhos para se pensar como podemos colocar em cena essas discussões, a partir de um sistema que apresenta em suas esferas educacionais, um ensino geralmente pautado no distanciamento da experiência cotidiana do educando.

Para o desenvolvimento das reflexões aqui postas faremos um estudo bibliográfico e experiencial, a partir da produção do conhecimento de alguns autores, tendo também como suporte os documentos oficiais: Brandão (2002), Candau (2002) Candau e Moreira (2007), Brasil, (2006, 2013, 2017), Silva (2008), Bego (2016) dentre outros.

Para o percurso metodológico optamos pela pesquisa qualitativa de caráter bibliográfico, alinhado as experiências docentes das autoras. De acordo com Flick (2009) os métodos qualitativos consideram a comunicação do pesquisador em campo como parte explícita da produção de conhecimento, em vez de simplesmente encará-la como uma variável a interferir no processo. A subjetividade do pesquisador, bem como daqueles que estão sendo estudados, tornam-se parte do processo de pesquisa.

Para Gil (2008) a principal vantagem da pesquisa de caráter bibliográfico reside no fato de permitir ao investigador a cobertura de uma gama de fenômenos muito mais ampla do que aquela que poderia pesquisar diretamente, permitindo fazer uma análise a partir de fontes que poderão alcançar alguns olhares e análises sobre as categorias eleitas para o objeto de estudo em questão.

A proposta deste artigo é trazer os possíveis encontros e desencontros entre o currículo e as manifestações de cultura popular. Trabalharemos o conceito de currículo e como as tradições populares podem fazer parte dos componentes curriculares de uma proposta educacional.

\section{Currículo e as manifestações de cultura popular: encontros e (de) encontros na formação e atuação do professor}

\footnotetext{
Rev. Pemo, Fortaleza, v. 2, n. 3, e233726, 2020

DOI: https://doi.org/10.47149/pemo.v2i3.3726

https://revistas.uece.br/index.php/revpemo

ISSN: 2675-519X

(c) (i) Esta obra está licenciada com uma Licença Creative Commons

Atribuição 4.0 Internacional.
} 
Para iniciar o diálogo entre o currículo e as manifestações culturais, comecemos a explanar o que se entende por currículo. Para Moreira e Candau (2007) a palavra currículo associa-se a distintas concepções, que derivam dos diversos modos de como a educação é concebida historicamente, bem como das influências teóricas que a afetam e se fazem hegemônicas em um dado momento. Diferentes fatores socioeconômicos, políticos e culturais contribuem, assim, para que o currículo venha a ser entendido como: (a) os conteúdos a serem ensinados e aprendidos; (b) as experiências de aprendizagem escolares a serem vividas pelos alunos; (c) os planos pedagógicos elaborados por professores, escolas e sistemas educacionais; (d) os objetivos a serem alcançados por meio do processo de ensino; (e) os processos de avaliação que terminam por influir nos conteúdos e nos procedimentos selecionados nos diferentes graus da escolarização.

O currículo pode ser visto como um caminho, uma direção para se trabalhar o processo de ensino e aprendizagem da escola. Configura-se como os conhecimentos produzidos por educadores/educandos no cenário educativo e as experiências que conseguem ser vivenciadas a partir deste fazer educativo, que parte dos conhecimentos formais associados as situações cotidianas. Uma relação entre o que se aprende na instituição escolar e aquilo que o aluno já constrói em suas interações com o meio em que vive. Sobre a forma de organização curricular as Diretrizes Curriculares Nacionais para a Educação Básica (2013), no Art. 13ํ, aponta:

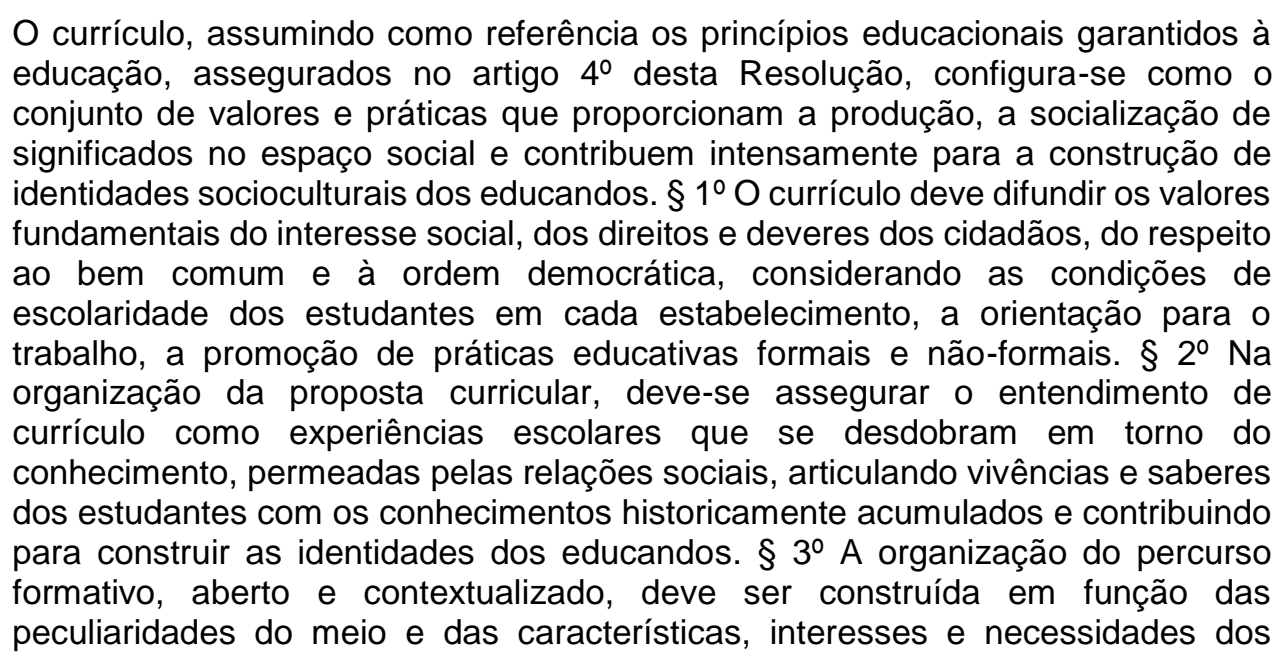

Rev. Pemo, Fortaleza, v. 2, n. 3, e233726, 2020

DOI: https://doi.org/10.47149/pemo.v2i3.3726

https://revistas.uece.br/index.php/revpemo

ISSN: 2675-519X 


\section{PRÁTICAS EDUCATIVAS, MEMÓRIAS E ORALIDADES}

Rev. Pemo - Revista do PEMO

estudantes, incluindo não só os componentes curriculares centrais obrigatórios, previstos na legislação e nas normas educacionais, mas outros, também, de modo flexível e variável, conforme cada projeto escolar. (BRASIL, 2013, p. 66).

Como percebemos o currículo deve assegurar experiências escolares que venham a contribuir com as relações sociais dos educandos e suas identidades, promovendo as práticas educativas, de caráter formal e não-formal, de acordo com cada projeto escolar. Entende-se, no entanto, que o currículo acaba sendo uma base e uma diretriz para que as escolas possam conduzir suas propostas pedagógicas, respeitando cada região que este currículo venha a ser desenvolvido.

Quando falamos em região e como este currículo deve ser desenvolvido, estamos nos referindo a relação entre o currículo e a diversidade cultural. De acordo com as DCNEBs (2013) no Art. 16, os componentes curriculares e as áreas de conhecimento devem articular em seus conteúdos, a partir das possibilidades abertas pelos seus referenciais, a abordagem de temas abrangentes e contemporâneos que afetam a vida humana em escala global, regional e local, bem como na esfera individual.

Dentre esses temas podemos destacar as manifestações de cultura popular. Nessa perspectiva a escola torna-se um espaço de socialização dos conhecimentos desta cultura popular, contemplando as diversidades culturais, sociais, com o compromisso de desenvolver pessoas criativas, reflexivas, longe de modelos pré-estabelecidos. Para que isso ocorra se faz necessário um repensar das práticas pedagógicas, ao reconhecer a multiplicidade de ações que envolvem a cultura popular. Esta deve atuar como um dos eixos centrais do processo curricular, indo para além das festividades folclóricas e as datas comemorativas, que geralmente são desenvolvidas na instituição escolar representando este segmento.

Segundo a Base Nacional Comum Curricular (2017) no ensino fundamental é necessário desenvolver no educando o senso estético para que o mesmo possa reconhecer, fruir e respeitar as diversas manifestações artísticas e culturais, das locais às mundiais, inclusive aquelas pertencentes ao patrimônio cultural da humanidade, bem como participar de práticas diversificadas, individuais e coletivas, da produção artísticocultural, com respeito à diversidade de saberes, identidades e culturas. 
Tal importância torna-se um desafio para os educadores quando eles precisam reconhecer, fortalecer e desenvolver esta cultura popular que se encontra comumente fora dos muros das instituições. Este desenvolvimento vai exigir da comunidade escolar práticas pedagógicas que valorizem, por exemplo, os trabalhos artísticos existentes não apenas nos livros didáticos, mas aqueles que são reais por se encontrarem nos espaços micros da comunidade conforme Brandão (2002, p. 92 -93) nos esclarece:

\begin{abstract}
As culturas do povo não existem como "coisas feitas", como um estado de, prontos, atrasados e acabados, sobre o qual o educador atua como o restaurador que recupera com outras cores o que sobrou de um velho quadro, obra de um pintor morto. [...] aquilo que parece ser um conjunto mais ou menos fragmentado de conhecimentos, arte, tecnologia rústica, sistema de crenças, mitos e rituais é, ao contrário, uma ativa estrutura social de produção simbólica que a cada dia de muitos modos se reproduz a si mesma, criando e recriando, preservando e modificando, fazendo circular entre uns e outros, através de redes de pessoas, grupos e instituições populares, tudo aquilo que pessoas reais, em situações concretas, fazem através de seus trabalhos culturais.
\end{abstract}

De fato, as culturas de um povo não são coisas prontas, mas algo que poderá constantemente ser repensado, recriado. Pensando neste processo que foge de um lugar pré-estabelecido, acreditamos que é daí que vigora as dificuldades de educadores. Não somente pelo seu processo formativo, pois este campo diverso e transversal vem sendo assegurado nas Diretrizes Curriculares para o Curso de Pedagogia publicadas no ano de 2006, mas a forma como a instituição escolar significa estas práticas populares e como os professores vão tecendo esses fazeres a partir da sua experiência de docência dialogada com as concepções de educação e escola que ele traz em sua bagagem teórica, metodológica e experiencial e as exigências do sistema educacional.

Acreditamos, assim como Soares (2018), que o professor atento, ao longo de sua experiência, é capaz de reorganizar e recriar a aula, desde que sua prática seja fundada numa epistemologia específica e delineada de acordo com a concepção de educação, formação humana e sociedade, mesmo que sua atuação docente seja atravessada por algumas limitações no que concerne ao papel docente que ele visa desempenhar, que implica nas mudanças que ocorrem na sociedade e no domínio de conhecimentos e 
posturas para atuar em um sistema educacional que possui suas exigências mercantilistas e que implicam diretamente na formação do professor.

Na concepção Junges, Ketzer e Oliveira (2018) em função dos novos tempos contemporâneos, que estão sempre em constantes mudanças, considerando ainda as não poucas dificuldades educacionais, dois dos fatores que deveriam ser preponderantes na prática docente são a compreensão e a flexibilização dos modelos pedagógicos, com a finalidade de inserir o indivíduo na sociedade, preparando-o para a autonomia e cidadania, com condições de agir e modificar o meio em que vive. Nesse sentido, somos levados a salientar a necessidade de revisões epistemológicas e metodológicas no campo educacional e formativo para criar possibilidades claras e fecundas para um contexto interdisciplinar ressignificador a partir dos princípios de uma sociedade democrática.

É importante refletirmos nessa conjuntura, assim como Vasconcellos e Bernardo (2016) que, como um país como o Brasil, com a proporção demográfica e a diversidade cultural, social e econômica que apresenta, ainda não alcançou um modelo único e nacional sobre qual seria a melhor formação a propiciar para esse educador, ou que modelos, caminhos, referenciais adotar para essa formação.

Para Bonifácio e Franco (2017) a ideia que predomina na formação e atuação do professor não é apenas a de atualização constante em face do acelerado processo de mudanças que vem ocorrendo na sociedade, seja no domínio do conhecimento e das tecnologias, ou mesmo no mercado de trabalho. Mas igualmente a de que o profissional docente é o protagonista desse processo, quem, como tal, deve, com o apoio, quer da escola, quer dos sistemas nacionais de educação, gerir e conduzir as ações que sustentam uma educação de qualidade social e pedagógica à altura das demandas atuais, que podem ser identificadas e apontadas a partir de uma diversidade cultural que deve ser reconhecida e debatida de forma democrática nas salas de aula mesmo diante das dificuldades e resistências encontradas.

Para Oliveira (2009) certamente tais dificuldades tem muito de debitarias da formação em que educadores estiveram e estão inseridos, havendo desde aí, o não reconhecimento e mesmo a deslegitimação das concepções e práticas que suportam as 
manifestações culturais populares, ou seja, há necessidade destas tradições serem discutidas no âmbito da formação de professores, mas principalmente que estas discussões possam ser legitimadas no espaço escolar, para que didaticamente elas possam fazer sentido para o professor, a sua formação e a instituição escolar. Neste sentido,

[...] incorporar os saberes de origem popular ao conhecimento acadêmico é uma necessidade cada vez mais premente, na medida em que, contemporaneamente, há uma estreita relação entre a valoração da experiência de vida de cada indivíduo com o processo ensino-aprendizagem e a democratização do saber. (SILVA, 2008. p. 41).

Os saberes de origem popular devem ter uma estreita relação com a proposta curricular de cada instituição escolar. Assim, os educandos terão a oportunidade de entrar em contato com as diversas culturas originadas nos espaços macro e micro e construírem seus saberes, pois somente os conteúdos oficiais, sem qualquer conexão com as situações cotidianas entrelaçadas aos costumes e crenças não conseguem ampliar o olhar dos alunos sobre o local em que estão inseridos. Sobre isso temos Brandão (2002, p. 36) que nos mostra como,

[...] nas culturas populares existem formas de educação extraescolar, cujo valor apenas agora começamos a descobrir. Tal como acontece com os povos indígenas, cantando e dançando, vendo como-se-faz-e-fazendo, jogando e trabalhando ao lado dos "mais velhos", os "mais jovens" convivem com aprendizados simples e complexos que vão dos segredos do plantio do milho até os de uma Folia de Santos Reis.

O encontro do currículo com as culturas populares permeia-se a partir das atividades extraescolares de acordo com o autor citado. Já nas DCNEBs (2013, p. 115116), elas são apontadas da seguinte maneira:

Quando os conhecimentos escolares se nutrem de temas da vida social, também é preciso que as escolas se aproximem mais dos movimentos que os alimentam, das suas demandas e encaminhamentos. Ao lado disso, a interação na escola entre os conhecimentos de referência disciplinar e aqueles provenientes das culturas populares pode possibilitar o questionamento de valores subjacentes em cada um deles e a necessidade de revê-los, ao mesmo tempo em que permite deixar clara a lógica que preside cada uma dessas formas de conhecimento e que os torna diferentes uns dos outros, mas não menos importantes.

Rev. Pemo, Fortaleza, v. 2, n. 3, e233726, 2020

DOI: https://doi.org/10.47149/pemo.v2i3.3726

https://revistas.uece.br/index.php/revpemo

ISSN: 2675-519X 
De acordo com as diretrizes curriculares para a educação básica a aproximação da cultura popular com os conhecimentos de referência disciplinar não deve se manter distantes. Pelo contrário, a proposta deste documento sinaliza que o currículo não deve se esgotar apenas nestes conhecimentos. Os componentes curriculares devem dialogar entre si, mantendo com isso uma interdisciplinaridade que levará o educando a ter um processo reflexivo a partir de todo o cenário que ele entra em contato ao estar na sala de aula e fora dela. A interdisciplinaridade,

[...] não dilui as disciplinas, ao contrário, mantém sua individualidade. Mas integra as disciplinas a partir da compreensão das múltiplas causas ou fatores que intervêm sobre a realidade e trabalha todas as linguagens necessárias para a constituição de conhecimentos, comunicação e negociação de significados e registro sistemático dos resultados. (BRASIL, 2006, p. 89).

Esta comunicação entre os conteúdos contribui para que o educador e educandos possam conhecer e valorizar a pluralidade cultural, pois o chão da escola pode ser concebido como um espaço onde muitas culturas se cruzam, embora na dinâmica escolar sempre esteja presente a

[...] dificuldade em lidar com a pluralidade e a diferença. Tende a silenciá-las e neutralizá-las. Sente-se mais confortável com a homogeneidade e a padronização. No entanto, abrir espaços para a diversidade, a diferença e para o cruzamento de culturas constitui o grande desafio que está chamada a enfrentar. (MOREIRA; CANDAU, 2003, p. 161).

Dentro desta pluralidade encontramos como um de seus componentes as manifestações culturais realizadas pelo povo que se localiza nos movimentos sociais, nas comunidades, tentando com isso dar sentido as criações e recriações a partir da memória do lugar, das tradições, dos elementos que possam representar o local em que eles estão inseridos. Daí, quando o aluno chega na escola e entra em contato com a discussão que envolve o patrimônio cultural imaterial, ele consegue fazer uma relação entre o que está sendo colocado na sala de aula pelo professor e o que ele consegue visualizar e vivenciar em sua comunidade. De acordo com Santomé (2005, p. 170):

É muito raro no espaço das salas de aula, que os professores desafiem os alunos e alunas a refletir e investigar as questões relacionadas com a vida e a cultura dos

Rev. Pemo, Fortaleza, v. 2, n. 3, e233726, 2020

DOI: https://doi.org/10.47149/pemo.v2i3.3726

https://revistas.uece.br/index.php/revpemo

ISSN: 2675-519X

(c) (i) Esta obra está licenciada com uma Licença Creative Commons

Atribuição 4.0 Internacional. 


\section{PRÁTICAS EDUCATIVAS, MEMÓRIAS E ORALIDADES}

Rev. Pemo - Revista do PEMO

grupos mais próximos do contexto local a que pertencem. Assim, os materiais e o próprio currículo não oferecem qualquer elemento com o qual esses educandos possam se identificar.

Com isso percebemos que a dimensão educativa foge de qualquer significado que o educando/a possa adquirir com as experiências escolares e fora dela, pois esta dimensão educativa e cultural costuma ser compreendida como algo dicotômico. Por este motivo as situações que os alunos e alunas vivenciam fora do espaço escolar acabam não tendo sintonia com o que eles entram em contato a partir da fala do professor e a leitura do livro didático.

O uso de elementos das manifestações das culturas populares na prática educativa deve acima de tudo levar o educando a reconhecer estas culturas populares e, a partir deste reconhecimento, construir sua concepção de mundo, pois toda aprendizagem é transformadora quando existe uma ação e uma reflexão consolidada a partir do contato com estas experiências que se dão fora dos muros da escola.

$\mathrm{Na}$ visão de Pansini e Nenevé (2008) ao entender a originalidade da cultura do aluno, da sua experiência de vida e de sua visão de mundo, o professor vai ao encontro de sua história local, da sabedoria das pessoas mais velhas, do conhecimento que não consegue adentrar as paredes das salas de aula, porque não é considerado legítimo dentro de uma prática pedagógica monocultural.

Portanto, não se trata de apenas reconhecer uma cultura local e pensá-la a partir do currículo e das práticas pedagógicas. É necessário que toda comunidade escolar esteja aberta a receber estas manifestações de cultura local e significá-las no processo de aprendizagem dos educandos e estes significarem ao entrarem em contato com as tradições populares de sua cidade, de seu bairro.

\section{3 considerações finais}

Neste artigo buscamos refletir e problematizar como a manifestação da cultura local atravessa os conteúdos das séries iniciais e de maneira consegue entrar em cena na proposta curricular e na atuação dos docentes, a partir do sistema educacional. 
Interessante notar que ao mesmo tempo em que há uma negação destes conteúdos por privilegiar aqueles que fazem parte do foco das avaliações em larga escala, na esfera pública, por exemplo, percebemos que alguns acadêmicos apontaram que tentam trabalhar a partir da disciplina de português. Outros acadêmicos que estão ocupando a esfera privada explanam que buscam significar as tradições populares, mas muitas vezes isso só se fortalece nas datas comemorativas.

Com isso vem o questionamento: Será que os professores conseguem trazer para a sala de aula todo esse cenário descrito por ter somente um dia (esfera pública) ou três dias (na esfera particular) para levantar essas discussões em sala? Nestes momentos é possível aprofundar? É provável que tudo isso acabe se resumindo as datas comemorativas.

Neste sentido, incorporar os saberes de origem popular ao conhecimento escolar é uma necessidade cada vez mais premente, na medida em que, contemporaneamente, há uma estreita relação entre a valoração da experiência de vida de cada indivíduo com o processo de ensino e aprendizagem e a democratização do saber. (SILVA, 2008).

Com este percurso é possível apontar possíveis possibilidades de encontros entre a cultura popular e os saberes constituídos na escola, desde que não se trate as manifestações da cultura popular como algo associado somente aos conteúdos oficiais, dentre eles o português, a matemática e a ciência, mas coloca-las em cena, a partir do cotidiano dos alunos e dos espaços que ele ocupa em sua cidade.

\section{Referências}

ARAÚJO, R. M.; ESTEVES, M. M. A formação docente, inicial e contínua, para o trabalho com adultos em Portugal: o olhar dos professores. Educação \& Formação, Fortaleza, v. 2, n. 1, p. 18-35, 2017. Disponível em: https://revistas.uece.br/index.php/redufor/article/view/121 Acesso em: 20 mar. 2020.

BEGO, A. Políticas públicas e formação de professores sob a perspectiva da racionalidade comunicativa: da ingerência tecnocrata à construção da autonomia profissional. Educação \& Formação, Fortaleza, v. 1, n. 2, p. 3-24, 2016. Disponível em: https://revistas.uece.br/index.php/redufor/article/view/98 Acesso em: 30 abr. 2020. 
BRANDÃO, Carlos Rodrigues. A Educação como Cultura. Campinas: Mercado das Letras, 2002.

BRASIL. Lei de Diretrizes e Bases da Educação Nacional. Brasília. MEC, 1996. 31p. Disponível em: <http://portal.mec.gov.br/arquivos/pdf/ldb.pdf>. Acesso em: 19 agost. 2019.

BRASIL. Ministério da Educação-MEC, Secretaria de Educação Básica. Orientações Curriculares para o Ensino Médio: Ciências da natureza, matemática e suas tecnologias. Brasília, 2006.

BRASIL. Diretrizes Curriculares Nacionais Gerais da Educação Básica. Ministério da Educação. Secretaria de Educação Básica. Diretoria de Currículos e Educação Integral. Brasília: MEC, SEB, DICEI, 2013.

FLICK, Uwe. Introdução a pesquisa qualitativa. Tradução Joice Elias Costa. 3. ed. Porto Alegre: Artmed, 2009.

GENÚ, M. A abordagem da ação crítica e a epistemologia da práxis pedagógica. Educação \& Formação, Fortaleza, v. 3, n. 3, p. 55-70, 2018. Disponível em: https://revistas.uece.br/index.php/redufor/article/view/856. Acesso em: 18 mar. 2020.

GIL, Antônio Carlos. Métodos e técnicas de pesquisa social. 6. ed. São Paulo: Atlas, 2008.

JUNGES, F. C.; KETZER, C.; OLIVEIRA, V. M. Formação continuada de professores: Saberes ressignificados e práticas docentes transformadas. Educação \& Formação, Fortaleza, v. 3, n. 3, p. 88-101, 2018. Disponível em: https://revistas.uece.br/index.php/redufor/article/view/858 Acesso em: 18 mar. 2020.

MOREIRA, Antônio Flavio Barbosa; CANDAU, Vera Maria. Educação escolar e culturas(s): construindo caminhos. Revista Brasileira de Educação. n. 23, p.156-168. 2003.

MOREIRA, Antônio Flavio Barbosa; CANDAU, Vera Maria. Indagações sobre currículo: currículo, conhecimento e cultura. Brasília: Ministério da Educação, Secretaria de Educação Básica, 2007.

OLIVEIRA, Milton Ramon. Escola e Cultura: Uma história de encontros e desencontros. In: CAVALCANTE, Maria Juraci Maia; VASCONCELOS, Raimundo Elmo de Paula; ARAUJO, José Edvar Costa; QUEIROZ, Zuleide Fernandes de. (Orgs). Escolas e Culturas: políticas, tempos e territórios de ações educacionais. Fortaleza: Edições UFC, 2009. 
PANSINI, Flávia; NENEVÉ, Miguel. Educação multicultural e formação docente. Revista Currículo sem Fronteiras, v.8, n.1, p-p.31-48, jan./jun., 2008.

SANTOMÉ, J. T. As culturas negadas e silenciadas no currículo. In: Silva, T. T. da. (Org.) Alienígenas na sala de aula: uma introdução aos estudos culturais em educação. Petrópolis, RJ: Vozes, 2005, p. 159-177.

SILVA, R.M. da C. (Org.). Cultura popular e educação: salto para o futuro. Brasília: Salto para o Futuro/TV Escola/Seed/MEC, 2008.

SOUZA, Maria de Lourdes Macena de. Sendo como se fosse: as danças dramáticas na ação docente do ator 2014. 296 f. Tese. (Doutorado em Artes) - Faculdade de Belas Artes, Universidade Federal de Minas Gerais. Belo Horizonte, 2014.

VASCONCELLOS, K. R.; BERNARDO, E. Profissionalização docente: reflexões e perspectivas no Brasil. Educação \& Formação, Fortaleza, v. 1, n. 2, p. 208-222, 2016. Disponível em: https://revistas.uece.br/index.php/redufor/article/view/109 Acesso em: 23 mai. 2020.

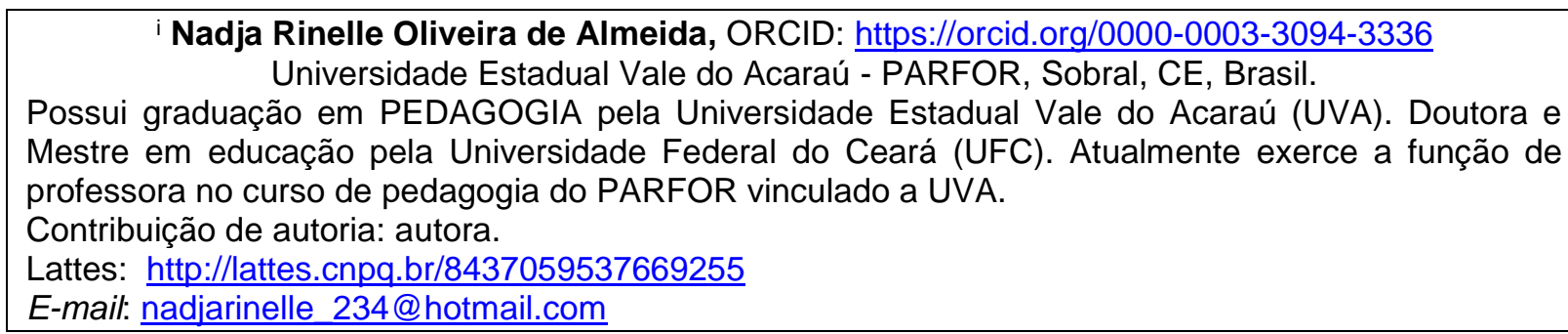

ii Damares de Oliveira Moreira, ORCID: https://orcid.org/0000-0002-9792-6584

Universidade Federal do Ceará, Fortaleza, CE, Brasil.

Possui graduação em Filosofia pela Universidade Federal do Ceará - UFC. Doutoranda em Educação Brasileira pela Universidade Federal do Ceará - UFC, Linha Trabalho e Educação.

Contribuição de autoria: revisão e tradução.

Lattes: http://lattes.cnpq.br/0522515557151497

E-mail: damares.abu@gmail.com

Editora responsável: Cristine Brandenburg

\section{Como citar este artigo (ABNT):}

ALMEIDA, Nadja Rinelle Oliveira de; MOREIRA, Damares de Oliveira. Manifestações da cultura popular local na aprendizagem das séries iniciais e na formação dos professores. Rev. Pemo, Fortaleza, v. 2, n. 3, e233726, 2020. Disponível em: https://revistas.uece.br/index.php/revpemo/article/view/3726 